
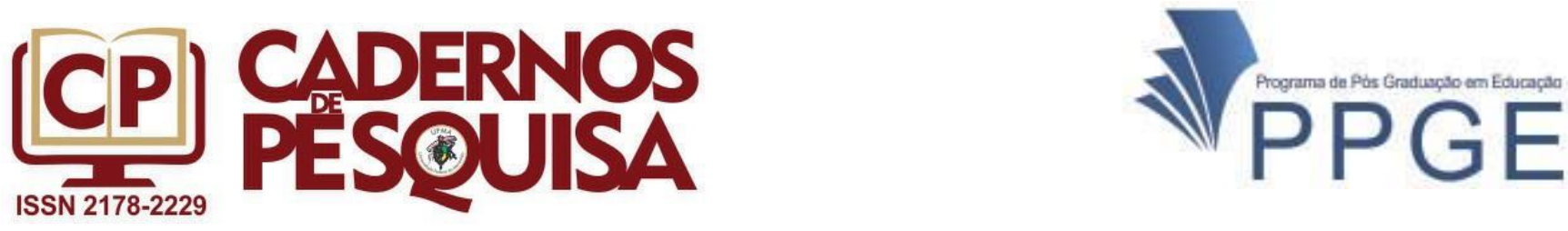

\title{
A discussão das relações étnico-raciais nos Programas de Pós-Graduação em Educação da Região Nordeste (2009-2016)
}

\author{
The discussion of ethnic racial relations in Postgradcate \\ Programs in Education of Northeast Region (2009-2016)
}

\section{La discusión de las relaciones étnicas raciales em los Programas de Posgrado em Educación de La Región Nordeste (2009-2016)}

\author{
Marcela Silva da Conceição ${ }^{1}$ \\ ORCID: http://orcid.org/0000-0001-8930-1499 \\ Wilma de Nazaré Baía Coelho ${ }^{2}$ \\ ORCID: http://orcid.org/0000-0001-8679-809X
}

Resumo: Este artigo tem como objetivo conhecer a discussão das relações étnico-raciais nos programas de pós-graduação em educação da região nordeste (2009-2016) através do levantamento da produção intelectual docente, da análise da estrutura e da organicidade dos programas. Este estudo auxiliará no reconhecimento do modus operandi dos programas frente as exigência dos marcos legais relacionados à diversidade e, especificamente, as relações étnico-raciais. As discussões amparam-se na teoria de Pierre Bourdieu (2007) por meio dos conceitos de campo e capital. Para a análise do conteúdo fizemos uso do estudo de Laurence Bardin (2011) mediante a organização das unidades, dos temas e por fim das categorizações. Inferimos que o campo da PósGraduação em Educação da região Nordeste vem investindo em capital científico para atender as demandas sociais e educacionais da região nordeste especificamente nas questões que envolvem o debate sobre as relações étnico-raciais. Podemos constatar o reflexo desse investimento na ampliação de linhas de pesquisa voltadas para a discussão racial e para as questões de diversidade como gênero, identidades, sexualidade, movimentos sociais, entre outros, que buscam, como afirma Silva (2008), atender aos problemas da sociedade e cumprir sua finalidade com o compromisso da

\footnotetext{
${ }^{1}$ Licenciada em Pedagogia pela Universidade da Amazônia, especialista em Educação Especial na perspectiva da Inclusão pela Faculdades Integradas Ipiranga e Mestra em Educação pela Universidade Federal do Pará. Professora da Educação Básica da Secretaria Municipal de Educação de Belém, desde 2012. Integrante do Núcleo de Estudos e Pesquisas sobre Formação de Professores e Relações Étnico-Raciais GERA/UFPA. E-mail: marceladaconceicao@yahoo.com.br

${ }^{2}$ Licenciada em Pedagogia pela Universidade da Amazônia, mestra em Educação pela Universidade da Amazônia, doutora em Educação pela Universidade Federal do Rio Grande do Norte. Professora da Universidade Federal do Pará, desde de 1994. Integra o corpo docente da Pós-Graduação em Currículo e Gestão da Escola Básica , do Programa em Educação em Ciências e Matemáticas e do Doutorado em Rede Educação na Amazônia. Vice-Coordenadora do EDUCANORTE e Líder do Núcleo de Estudos e Pesquisas sobre Formação de Professores e Relações Étnico-raciais(GERA). Bolsista de Produtividade em Pesquisa do CNPq - Nível 2. E-mail: wilmacoelho@yahoo.com.br
} 
vida social. As avaliações da CAPES, também, refletem tal investimento quando apresentam significativos progressos no crescimento da produção intelectual desta região.

Palavras-chave: Programa de Pós-Graduação. Relações Étnico-Raciais. Produção Intelectual. Região Nordeste.

Abstract: This aticle aimstoknow thw discussion of the ethnic racial relations in postgraduate
programs in education of northeast region (2009-2016) by means of the survey of techer intelectual
production, structure analysis and organicity of the modus operandi oh the programs against the
requirements of legal frameworks related to diversity and specifically, the ethnic-racial relations. The
discussion supported in theory of Bourdieu (2007) by means of the concepto field and capital. For
content analysis wemadg use of study of Bardin ( 2011$)$ upon the organization of the units, of the
themes and lastly of categorizations. We infer tha the field of postgradua te education in the northeast
region has been investing in scientific capital to meet the social and educational demands of the
northeast region specifically on the issues surrocinding the debate on ethnic-racial relations. We can
seg the reflection of this investtment in the expansion of research lines focused on racial discussion
for diversity issues as gere, identities, sexuality, social movements among others, who seek as claims
Silva (2008), address the problems of society and fulfill your purposg with the commitment of social
life. The ratings of CAPES, also, reflect such investment whe they show significant progress in the
growth of intellectual production in the region. Keywords: Postgraduate Program. Ethnic Racial Relations. Intellectual Production. Northcast Region.

Resumen: Este artículo tiene como objetivo conocer la discusion de las relaciones étnicas raciales em los programas de posgrado em educación de lá región nordeste (2009-2016) por médio del levantamento de la producción intelectual docente, análisis de la estrutura, de la organización de los programas. Este estúdio auxiliar em el reconocimiento del modus operand de los programa frente a la exigência de los marcos legales relacionados a la diversidade y, especificamente, las relaciones étnicas raciales. Las discusiones se amparan em la teoría de Pierre Bourdieu (2009) por médio de los conceptos de campo y capital. Para la análisis del contenido hicimos uso del estudio de Laurence Bardin (2011) sobre de la organización de las unidades, de los temas y por fin de las categorizaciones. Hemos inferido que el campo de posgrado em educación de la región nordeste viene invirtigando em capital científica para atender las demanda sociales y educacionales de la región nordeste especificamente em las questiones que implican debate sobre las relaciones étnica raciales. Podemos constatar el reflejo de esta inversión em la ampliacion de las líneas de pesquisa enfocado para la discusión racial y para las cuestiones de diversidad como género, identidades, sexualidade, movimentos sociales, entre otros, que buscan como assegura Silva (2008), atender los problemas de la sociedade y cumplir su propósitocon el compromisso de la vida social. las evoluciones de la CAPES. También, reflejantal inversión cuando presentan significativos progresos em el crecimiento de la producción intelectual de esa región.

Palabras clave: Programa de Posgrado. Relaciones Étnica-Raciales. Producción Intelectual. Región Nordeste.

\section{INTRODUÇÃO}

As políticas públicas de reconhecimento e valorização da história e cultura da população negra no Brasil, conquistadas nos últimos anos, tem protagonizado o papel das instituições de ensino na desconstrução dos estereótipos e no combate ao preconceito e racismo no âmbito escolar, mais especificamente nas situações que envolvem os processos de formação (inicial e continuada) de professores e as práticas pedagógicas discriminatórias. Fato é que a alteração da forma de trabalhar os conteúdos pelos professores pode auxiliar significativamente na problematização 
do preconceito e da discriminação em relação aos grupos historicamente excluídos e invisibilizados. (SANTOS, 2015).

Assumir este papel, nas instituições, não se configura como uma tarefa fácil, por duas razões: em primeiro lugar porque exige uma ação coletiva entre todos os agentes; em segundo lugar, por requerer qualificação dos agentes em relação à temática e suas especificidades, e, ainda, em relação aos domínios pedagógicos.

Por estas razões, as instituições de ensino, comprometidas com a formação humana em diferentes fases da vida, assumem papel relevante nesse processo de reconhecimento e valorização da cultura afro-brasileira e africana quando passam a promover o desenvolvimento de práticas pedagógicas sistemáticas associadas aos projetos pedagógicos, os quais, por sua vez, auxiliam no enfrentamento do racismo, da discriminação e do preconceito, muitas vezes, velado, nestas instituições e na sociedade.

Daí a relevância dos programas de pós-graduação em educação (PPGE’s) na qualificação desses agentes para a discussão racial uma vez que estes são responsáveis pela formação continuada de professores-pesquisadores atuantes em diferentes níveis de ensino. Neste cenário, os programas assumem, entre outras atribuições, a função de fomentar as pesquisas, o desenvolvimento e inovação tecnológica na temática das relações étnico-raciais, contribuindo assim, com a construção de uma escola plural e republicana. (BRASIL, 2009).

Diante deste cenário, a produção intelectual se constitui em uma ferramenta indispensável na alteração de atitudes, posturas e valores que eduquem cidadãos quanto à pluralidade étnico-racial (BRASIL, 2004). Por isto, o exame dos PPGE's se fez necessário, pois uma parte significativa dos agentes destes Programas são docentes atuantes na Educação Básica e no Ensino Superior. Contudo, nem sempre os objetos estudados por esses discentes-docentes refletem os problemas reais da Educação Brasileira. (COELHO, 2015). Assim, quanto maior o debate acerca desse paradoxo, maior a possibilidade de discussão e reversão desse quadro. Esta ponderação faz-se necessária, pois consideramos que o professor da Educação Básica e do Ensino Superior, ao ser instado a pensar, de modo circunstanciado, acerca da sua prática pedagógica como objeto de sua dissertação ou tese, terão as ferramentas pedagógicas necessárias para fazer frente a tais problemas, de modo a enfrentá-los e subvertê-los. 
Em face dos aspectos mencionados, reiteramos a necessidade de conhecer 0 modus operandi dos PPGE's da região Nordeste do país haja vista que esta região tem sido a que mais tem se desenvolvido no tocante à Pós-Graduação, segundo reflexão realizada por Ramalho e Madeira (2005). Além de apontarem a expansão deste nível de ensino no Brasil, e, especificamente na região Nordeste, destacam que tal desenvolvimento se deu, também, em caráter qualitativo e quantitativo.

Este aspecto tem sido evidenciado, também, na Região Norte a partir do estudo realizado por Coelho e Silva (2016) que revelam certa regularidade no volume de produção e na variedade de temas produzidos nesses programas, o que consequentemente, refletem em resultados qualitativos e quantitativos uma vez que estas produções se constituem um dos critérios para a qualidade de excelência destes programas.

Neste sentido, empreendemos esforços na investigação do mapeamento da produção intelectual docente bem como da estrutura e organização dos PPGE's da região Nordeste das seguintes universidades: Universidade Federal do Ceará (UFC), Universidade do Federal da Bahia (UFBA), Universidade Federal de Pernambuco (UFPE), Universidade Federal Rio Grande do Norte (UFRN) e Universidade Federal Rural de Pernambuco (UFRPE).

A investigação incidiu em quatro etapas, sendo que a primeira consistiu na consulta a Plataforma Sucupira para o levantamento das propostas dos programas. Na segunda etapa recorremos à página da Web dos programas para a investigação da composição do quadro de professores permanentes e colaboradores. Na terceira etapa, realizamos consulta ao Currículo Lattes dos docentes para traçar o perfil acadêmico e profissional dos mesmos. E, a última etapa consistiu na sistematização e análise dos dados que consubstanciaram a investigação no tocante a discussão das relações étnico-raciais nos PPGE's.

\section{O CONTEXTO DA PÓS-GRADUAÇÃO NO BRASIL: notas introdutórias}

O ano de 1965 representa um marco histórico para a educação brasileira em virtude de dois aspecto: primeiramente, pela expansão de mais um nível de ensino na educação escolar no Brasil com a implantação dos Programas de PósGraduação (PPG's) nas redes federais de ensino, regulamentados pelo Parecer N. 977/1965, mais conhecido como o Parecer Sucupira, que estabeleceu a estrutura, a 
organização e o funcionamento dos PPG's no Brasil. Em segundo lugar, por este nível de ensino se tornar o foco das políticas de apoio ao desenvolvimento tecnológico e científico do país. (BALBACHEVSKY, 2005).

A literatura especializada, por meio de autores como Saviani (2000), Santos (2003), Balbachevsky (2004), Nosella (2005), Morosini (2009), Coelho e Silva (2016) apontam justificativas diversas para a institucionalização dos PPG's nas universidades. Entretanto, há um consenso entre esses pesquisadores de que este nível de ensino se tornou um espaço de formação humana qualificável para o desenvolvimento de um projeto de modernização por se transformar em um mecanismo potencial para o desenvolvimento da ciência e da tecnologia no Brasil. Em razão disso, os PPG's se expandiram expressivamente a partir de 1970 com o apoio do governo militar, que almejava "criar um projeto de modernização conservadora para sociedade brasileira" (RAMALHO; MADEIRA, 2005, p. 71), intensificando, assim, o aumento nos investimentos financeiros e, sobretudo, na qualidade da oferta dos cursos, tanto em "infraestrutura quanto na formação e profissionalização dos pesquisadores" (FARIAS FILHO, 2013, p. 290). Isso vem impactando, ao longo dos anos, em melhores resultados nas avaliações nacionais em relação aos outros níveis de ensino (WASSEN; PEREIRA; BALZAN, 2015).

Esta iniciativa resultou no fomento à pesquisa acadêmica em diferentes áreas do conhecimento, como Ciências Humanas, Ciências da Natureza, Ciências da Vida, entre outras, atendendo ao proposto nos Planos Nacionais de Pós-Graduação (PNPG), que traçavam metas para aperfeiçoar a institucionalização deste nível de ensino.

Em contrapartida tal ação impulsionou de forma assimétrica a expansão desse nível de ensino nas regiões do país. Um dos aspectos que influenciaram essas disparidades, de acordo com Wassen, Pereira e Balzan (2015), é resguardado pelos critérios estabelecidos no Parecer Sucupira N. 977/1965, e se apresenta como uma das principais razões para as desigualdades regionais em relação à institucionalização dos PPG'S em instituições de Ensino Superior. Eles destacam que os PPG's só poderiam ser implantados em instituições de educação superior que tivessem atingido um mínimo de desenvolvimento em infraestrutura, recursos humanos e financeiros. Desse modo, as universidades que atendiam a tal critério concentravam-se nas regiões economicamente mais desenvolvidas, como as regiões Sudeste e Sul. 
Essas assimetrias regionais atravessaram toda a história do PPG'S no Brasil e têm sido apontadas como um dos elementos utilizados nos PNPG nos processos de elaboração de metas com vista a reversão dessas disparidades. Embora esses mecanismos apontem resultados positivos, tanto em quantidade como em qualidade, estudiosos do campo (SAVIANI, 2000; NOSELLA, 2005; RAMALHO; MADEIRA, 2005; FÁVERO, 2009; WASSEM; PEREIRA; BALZAR, 2015) afirmam que as disparidades regionais ainda impactam o desempenho e a qualidade dos PPG's das regiões Norte, Nordeste e Centro-Oeste, que concentram o menor número de programas e de produções em relação às regiões Sudeste e Sul.

A despeito desse processo, Balbachevsky (2005) argumenta que as políticas de reparações estabelecidas pela CAPES não conseguem eliminar as assimetrias regionais porque assumem uma postura paternalista ao reservar recursos apenas para as regiões Norte e Nordeste, criando uma espécie de mercado protegido com níveis de exigência menores com premiações para os programas mais fracos.

Os diferentes posicionamentos e a produção de pesquisadores do campo da Pós-Graduação no Brasil têm constituído uma relevante ferramenta para a elaboração de políticas públicas neste campo, haja vista que essas políticas, segundo Farias Filho (2013), têm por base os conhecimentos produzidos e acumulados nas últimas décadas nos programas, o que reitera a relevância dessa produção na definição de políticas públicas e na melhoria da qualidade do ensino.

A exemplo, podemos destacar o crescimento da produção intelectual acerca das relações étnico-raciais no Brasil (BRITO, 2018) em razão, especialmente, do ingresso de pesquisadores e ativistas negros em universidade públicas. Fato que contribuiu consubstancialmente para a conquista de políticas públicas de reconhecimento e valorização da história e cultura da população afro-brasileira como a Lei de Cotas, a Lei N. 10.639/2003 e a Lei N. 11.645/2008.

Essas Leis representam um mecanismo de subversão das estruturas de poder instaladas nos sistemas de ensino e a possiblidade de ressignificar pensamentos, noções, atitudes formuladas com base em preconceitos que desqualificam pessoas negras, e, acima de tudo, descolonizar a ciência, que sempre se pautou em uma perspectiva eurocêntrica (COELHO; SILVA, 2016).

O crescimento da produção sobre as relações étnico-raciais representa um indicativo da legitimação desse objeto de estudo nos PPG's haja vista que a história desses programas foi marcada por uma hierarquia de objetos (BOURDIEU, 2007) 
que privilegiou temas como cultura escolar, formação de professores, livros didáticos, disciplinas escolares, currículo, práticas educativas, questões de gênero, infância e instituições escolares (NOSELLA, 2010) nas primeiras décadas de sua institucionalização.

Com a reestruturação dos PPG's, especialmente nas décadas de 1980 e 1990, surgem os grupos de pesquisas e as linhas de pesquisas como critério de credenciamento e autorização dos programas. Os temas $e$ as áreas de concentração já não eram mais o foco da organização dos programas, mas sim os problemas colocados pela realidade social e educacional que começaram a impactar na definição das linhas de pesquisas imprimindo uma identidade aos PPG's demonstrando sua particularidade e interesse de pesquisa (WASSEM, PEREIRA E BALZAN, 2015).

Além da construção dessa identidade ressaltamos, ainda, a relevância que a articulação entre produção intelectual, linha pesquisa e área de concentração assume como um instrumento indispensável para o funcionamento orgânico dos PPG's, uma vez que este nível de ensino se constituiu em um espaço de pesquisa e produção de conhecimento que precisa estar em íntima articulação com suas linhas e áreas de pesquisa (COELHO; SILVA, 2016, p. 391) impactando de modo consubstancial em sua avaliação e consequentemente em seu funcionamento.

Observamos, neste percurso, os avanços que o campo da PPG's vem alcançando nos últimos, especialmente quando se trata da produção intelectual, pois entre as principais regras deste campo podemos dizer que em termos quantitativos e qualitativos a produção intelectual está entre as principais delas, uma vez que ela tem se tornado a "espinha dorsal" da organização e da estrutura dos PPG's.

Frente à relevância desses aspectos para a organização e funcionamento dos PPG's, buscaremos empreender esforços para a investigação da produção intelectual docente, da estrutura e da organização dos programas da UFC, UFBA, UFPE, UFRN e UFRPE que compõe o nosso escopo de investigação. 


\section{PROGRAMAS DE PÓS-GRAduAÇÃo EM EDUCAÇÃO NA REGIÃo NORDESTE}

A institucionalização da Pós-Graduação em Educação na região Nordeste aconteceu em 1971 e tem avançado nas últimas décadas tanto em quantidade como em qualidade (RAMALHO; MADEIRA, 2005). Na perspectiva de Ramalho e Madeira (2005), os avanços têm acontecido em diferentes áreas, como na capacitação docente, na formação de profissionais de alto nível, na redução do tempo médio de titulação na Pós-Graduação, na reorganização da estrutura de financiamento da Pós-Graduação, no aprimoramento constante da qualidade dos programas e na proposição de ações para reduzir o desequilíbrio regional.

$O$ indicativo de desenvolvimento nos programas da região nordeste, nos últimos anos, apontado por Ramalho e Madeira (2005) decorre das políticas de indução de financiamento como a Procad, Procad novas fronteiras, Acelera Amazônia e Dinter Novas fronteiras e dos editais e ações de fomento promovida pela CAPES nos últimos, investindo assim em recursos de custeio e de capital para pesquisas na fronteira do conhecimento e da formação de pessoas (BRASIL, 2010).

O impacto dessas políticas pode ser compreendido no resultado das últimas avaliações realizada pela CAPES no qual a região nordeste vem apresentando progressivo crescimento. Em 2010, o resultado da avaliação indicou que os PPG's na região nordeste chegou a um crescimento 31,3\%, em 2013 o aumento alcançou um percentual de $33 \%$ e em 2017 o desenvolvimento obteve o resultado de $21 \%$. Conforme podemos acompanhar, a região Nordeste apresentou variação de crescimento nos diferentes períodos, o que significa que houve avanços, mas com indicativos de novas estratégias para que a região mantenha seu crescimento para os próximos períodos.

Como podemos perceber, as políticas de apoio à melhoria da qualidade dos PPG's têm se refletido nos resultados das avaliações dos programas nos últimos anos, já que atualmente a avaliação é "[...] considerada uma importante referência de qualidade dos Programas de Pós-Graduação brasileiros" (WASSEN; PEREIRA; BALZAN, 2015, p. 218), transformando esses campos em espaços de disputa pela excelência da qualidade e pela produção intelectual, que representa, na perspectiva bourdieusiana, uma estratégia política de investimento objetivamente orientada para a maximização do lucro propriamente científico. 
Em 2016, algumas universidades da região Nordeste foram classificadas, por meio das avaliações internacionais, entre as melhores instituições do mundo e da América Latina. Uma das avaliações foi realizada pelo Center for World University Rankings (CWUR), que se constitui como um levantamento internacional que lista anualmente as mil melhores universidades do mundo. A UFBA e a UFPE foram incluídas nesta lista ${ }^{3}$. A segunda avaliação foi realizada pela QS Media Research, que visa à excelência de padrão internacional, classificando as melhores universidades da América Latina. A região Nordeste teve 13 estabelecimentos de Ensino Superior selecionados dentre as 89 universidades brasileiras ${ }^{4}$.

Além dos avanços conquistados nos últimos anos em relação à expansão da Pós-Graduação na região Nordeste, vale destacamos as informações acerca dos pesquisadores dos pesquisadores e suas respectivas produções científicas. Quanto ao quadro docente, investigamos o total de 243 pesquisadores, sendo 145 do sexo feminino e 98 do sexo masculino. Nos cinco programas analisados, o quantitativo de professoras supera o de professores. A incidência desses dados se repete em relação à produção intelectual, por sexo, desses profissionais, uma vez que as professoras alcançaram um percentual de $58 \%$, enquanto os professores apresentaram um percentual de $42 \%$.

Estudar a produção intelectual reveste-se da maior importância uma vez que as produções científicas em suas várias manifestações e materializações são mecanismos de difusão e democratização das ações da academia perante a sociedade (CURTY, 2010, p. 06). Deste modo, entendemos que estudar a produção intelectual docente da região Nordeste permite-nos conhecer as ações das universidades frente as marcos legais no tocante a discussão da educação das relações étnico-raciais. Neste sentido apresentaremos, a seguir, os dados referentes ao mapeamento da organização e produção intelectual dos Programas de PósGraduação em Educação da região Nordeste ${ }^{5}$.

\footnotetext{
${ }^{3}$ Informação disponível em: https://www.ufba.br/noticias/ranking-mundial-coloca-ufba-como-melhoruniversidade-do-nordeste-brasileiro, Acesso em: 04 abr. 2018.

${ }^{4}$ Disponível em: http://www.revistanordeste.com.br/noticia/brasil/revista+nordeste+traz, Acesso em: 28 jul. 2018.

${ }^{5}$ As informações acerca da institucionalização dos programas de pós-graduação em educação da região nordeste, objeto desta pesquisa, tiveram como fonte principal as propostas dos programas disponíveis no site da CAPES. A fonte completa encontra-se nas referências deste artigo.
} 


\section{PROGRAMA DE PÓS-GRADUAÇÃO EM EDUCAÇÃO DA UFBA}

O curso de Mestrado da Universidade Federal da Bahia inaugurou suas atividades em 1980, na Faculdade de Educação, com a área de concentração em Pesquisa Educacional. Em 1992, 12 anos depois da institucionalização do Mestrado, o curso de Doutorado foi implantado, mas seu reconhecimento aconteceu somente em 1995.

Ao longo do tempo, o programa reestruturou sua proposta curricular no sentido de "atender a dinâmica da produção do conhecimento no mundo contemporâneo" (CAPES, 2017) e deste modo buscou a configuração de novas linhas de pesquisa e novos grupos de pesquisas, visando, assim, maior consistência entre esses elementos.

Notamos, também, ações desenvolvidas com foco para a Educação Básica, seja por meio de projetos de extensão, ofertas de cursos, seminários entre outros destinados aos professores da Educação Básica. Entre as metas estabelecidas e atingidas pelo programa, citamos a nota cinco na avaliação da CAPES na última avaliação quadrienal. No Quadro I apresentaremos as informações no tocante o perfil da formação docente do PPGE da UFBA.

\section{Quadro 1 - Perfil da formação docente - UFBA}

\begin{tabular}{|c|l|}
\hline $\begin{array}{c}\text { No } \\
\text { Docente }\end{array}$ & O quadro docente é composto 48 doutores, sendo 28 mulheres e 20 homens. \\
\hline $\begin{array}{c}\text { Formação } \\
\text { Inicial }\end{array}$ & $\begin{array}{l}15 \text { em Pedagogia e } 33 \text { em outras áreas: Biologia, Arquitetura, Agronomia, } \\
\text { Engenharia Civil, Psicologia, Filosofia, História, Educação Física, Matemática, } \\
\text { Economia, Ciências Sociais, Biologia, Geografia, Arte, Letras, Licenciatura de } \\
\text { Primeiro Grau, Fonoaudiologia, Teologia e Serviço Social. }\end{array}$ \\
\hline $\begin{array}{c}\text { Formação } \\
\text { Doutoral }\end{array}$ & $\begin{array}{l}71 \% \text { em Educação e 29\% outras áreas: como Biologia, Arquitetura, Agronomia, } \\
\text { Engenharia Civil, Psicologia, Filosofia, História, Educação Física, Matemática, } \\
\text { Economia, Ciências Sociais, Geografia, Arte, Letras, Licenciatura de Primeiro Grau, } \\
\text { Fonoaudiologia, Teologia e Serviço Social. }\end{array}$ \\
\hline $\begin{array}{c}\text { Instituição } \\
\text { Formadora } \\
\text { Doutoral }\end{array}$ & $\begin{array}{l}41 \% \text { UFBA; 12\% UNICAMP e PUC/SP respectivamente; 4\% a UFSCAR; cada } \\
\text { Universidade alcançou o percentual de 3\%, sendo elas, a universidade UFGM, }\end{array}$ \\
\hline $\begin{array}{c}\text { Década da } \\
\text { Uormação } \\
\text { Doutoral }\end{array}$ & O ano de 2000, 60\%; $1990,36 \%$ e 4\% em 1980 e 1970. \\
\hline
\end{tabular}

Fonte: Consulta ao Currículo Lattes em fevereiro/março de 2017.

O resultado do levantamento em relação à produção intelectual docente pode ser acompanhado nas tabelas 1, 2 e 3. 
Tabela 1 - Produção intelectual docente UFBA - Artigos

\begin{tabular}{lccccccccc}
\hline DOCENTE & $\mathbf{2 0 0 9}$ & $\mathbf{2 0 1 0}$ & $\mathbf{2 0 1 1}$ & $\mathbf{2 0 1 2}$ & $\mathbf{2 0 1 3}$ & $\mathbf{2 0 1 4}$ & $\mathbf{2 0 1 5}$ & $\mathbf{2 0 1 6}$ & TOTAL \\
\hline Professores & 6 & 12 & 18 & 23 & 30 & 25 & 25 & 29 & 168 \\
Professoras & 26 & 36 & 23 & 39 & 39 & 52 & 33 & 34 & 282 \\
\hline
\end{tabular}

Fonte: Consulta ao Currículo Lattes em fevereiro/março de 2017.

Tabela 2 - Produção intelectual docente UFBA - Livros

\begin{tabular}{lccccccccc}
\hline DOCENTE & $\mathbf{2 0 0 9}$ & $\mathbf{2 0 1 0}$ & $\mathbf{2 0 1 1}$ & $\mathbf{2 0 1 2}$ & $\mathbf{2 0 1 3}$ & $\mathbf{2 0 1 4}$ & $\mathbf{2 0 1 5}$ & $\mathbf{2 0 1 6}$ & TOTAL \\
\hline Professores & 15 & 8 & 7 & 18 & 4 & 9 & 8 & 8 & 77 \\
Professoras & 10 & 7 & 13 & 10 & 10 & 13 & 4 & 2 & 68 \\
\hline
\end{tabular}

Fonte: Consulta ao Currículo Lattes em fevereiro/março de 2017.

Tabela 3 - Produção intelectual docente UFBA - Capítulos de livro

\begin{tabular}{lccccccccc}
\hline DOCENTE & $\mathbf{2 0 0 9}$ & $\mathbf{2 0 1 0}$ & $\mathbf{2 0 1 1}$ & $\mathbf{2 0 1 2}$ & $\mathbf{2 0 1 3}$ & $\mathbf{2 0 1 4}$ & $\mathbf{2 0 1 5}$ & $\mathbf{2 0 1 6}$ & TOTAL \\
\hline Professores & 49 & 13 & 29 & 59 & 12 & 39 & 15 & 22 & 275 \\
Professoras & 59 & 49 & 48 & 40 & 18 & 25 & 38 & 26 & 303 \\
\hline
\end{tabular}

Fonte: Consulta ao Currículo Lattes em fevereiro/março de 2017.

Os resultados sinalizam que nas produções de artigos e capítulos de livros, as professoras assumem a liderança. Esse quadro se diferencia apenas na produção de livros, em que os professores assumem a dianteira. No entanto, percebe-se uma diminuição em relação ao número de artigos publicados no período de 2009 até 2013. Para os professores e professoras, tal fenômeno dura até 2011. A partir desse ano, a produção de artigos oscila a cada ano.

Em relação à produção de livros, evidenciamos que os professores apresentam uma diminuição entre 2009 e 2011. O ano de 2012 concentra o maior número de publicações de livros, somando 18, e, a partir de 2013, há um equilíbrio na quantidade de publicações. Quanto à publicação das professoras, há certo equilíbrio entre 2009 e 2014.

Quanto à produção de capítulos de livro, podemos perceber um decréscimo na produção das professoras até em 2013. Com relação à produção dos professores, a oscilação é constante desde 2009. Podemos observar que os anos de 2009 e 2012 foram aqueles que concentraram o maior número de publicações nas duas categorias.

Atualmente, o programa apresenta como área de concentração Educação, Sociedade e Práxis Pedagógica sendo composta por cinco linhas de pesquisa, são 
elas: Currículo e (In)formação; Linguagens, Subjetivações e Práxis Pedagógica; Política e Gestão da Educação; Educação, Cultura Corporal e Lazer e Educação e Diversidade. Vejamos, a seguir, no Quadro 2, as linhas de pesquisa com suas respectivas temáticas.

Quadro 2 - Linhas de pesquisa e temáticas estudadas - UFBA

\begin{tabular}{|l|l|}
\hline Linhas de pesquisa & \multicolumn{1}{c|}{ Temáticas estudadas } \\
\hline $\begin{array}{l}\text { Linguagem, } \\
\text { subjetivações e práxis } \\
\text { pedagógica }\end{array}$ & $\begin{array}{l}\text { Diversidade, filosofia, ciências da linguagem, ciências da educação em } \\
\text { ações de ensino e práxis pedagógica. }\end{array}$ \\
\hline $\begin{array}{l}\text { Política e gestão da } \\
\text { educação }\end{array}$ & $\begin{array}{l}\text { Políticas públicas, planejamento, gestão, financiamento e avaliação da } \\
\text { Educação Básica, financiamento e avaliação do Ensino Superior, } \\
\text { sistemas de ensino presencial e à distância. }\end{array}$ \\
\hline $\begin{array}{l}\text { Currículo e } \\
\text { (in)formação }\end{array}$ & $\begin{array}{l}\text { Currículo, formação docente, conhecimento, cultura e comunicação, nos } \\
\text { seus aspectos epistemológicos, históricos, sociopolíticos, institucionais, a } \\
\text { prática educacional. }\end{array}$ \\
\hline $\begin{array}{l}\text { Educação, cultura } \\
\text { corporal e lazer }\end{array}$ & $\begin{array}{l}\text { Práxis pedagógica, formação de professores, políticas públicas, corpo, } \\
\text { cultura, etnias, mídia, memória, imagem, esporte, lazer, } \\
\text { infância/juventude. }\end{array}$ \\
\hline $\begin{array}{l}\text { Educação e } \\
\text { diversidade }\end{array}$ & $\begin{array}{l}\text { Educação, currículo, formação docente, prática pedagógica, gênero, } \\
\text { etnias, classes sociais, necessidades especiais, arte e ludicidade. }\end{array}$ \\
\hline
\end{tabular}

Fonte: Consulta a proposta do programa no período de fevereiro/março de 2017.

\section{PROGRAMA DE PÓS-GRADUAÇÃO EM EDUCAÇÃo DA UFC}

A Universidade Federal do Ceará inaugurou seu curso de Mestrado em 1977, na cidade de Fortaleza. Em 1993, 16 anos após a criação do Programa de PósGraduação, iniciaram as atividades da primeira turma do curso de Doutorado em Educação, consolidando-se, assim, a pesquisa, o ensino e a extensão na Faculdade de Educação. No decorrer da existência do Programa o foco da pesquisa sofreu alteração em razão das demandas sociais.

Primeiramente, iniciou suas atividades com área de concentração no Ensino na perspectiva da integração curricular. "O programa hoje apresenta características e necessidades das mais diversas, esforçando-se por articular a discussão educacional nas mais diferentes dimensões, tanto micro quanto macro educacional" (CAPES, 2017) neste sentido, também, visa atender as recomendações de mudança da CAPES, no atual contexto a área de concentração consiste na Educação Brasileira. 
No que diz respeito à avaliação do programa pela CAPES, o programa vem se mantendo nas três últimas avaliações - Trienal 2010, Trienal 2013 e Quadrienal 2017 - com nota quatro, o que nos leva a inferir que o nível de produção deste programa vem se mantendo com a mesma frequência.

Quadro 3 - Perfil da formação docente - UFC

\begin{tabular}{|c|c|}
\hline $\begin{array}{l}\text { № } \\
\text { Docente }\end{array}$ & 82 doutores, sendo 41 mulheres e 41 homens \\
\hline $\begin{array}{l}\text { Formação } \\
\text { Inicial }\end{array}$ & $\begin{array}{l}20 \text { docentes com formação em Pedagogia, } 6 \text { não identificados e } 56 \text { em outras } \\
\text { áreas: Arquitetura e Urbanismo, Engenharia Agrônoma, Engenharia Civil, } \\
\text { Engenharia Mecânica, Engenharia Química, Engenharia Mecânica, Psicologia, } \\
\text { Filosofia, História, Educação Física, Matemática, Economia, Ciências Sociais, } \\
\text { Geografia, Língua Estrangeira Aplicada, Letras Anglo Germânicas, Direito, } \\
\text { Odontologia, Administração, Biologia, Música, Computação, Ciências Sociais, } \\
\text { Ciências Econômicas, Arte, Serviço Social, Letras, Comunicação. }\end{array}$ \\
\hline & $\begin{array}{l}\text { Educação com } 63 \% \text { do total, enquanto as demais áreas somaram } 27 \% \text {, assim } \\
\text { distribuídas: História, Psicologia Escolar, Antropologia, Arte, Engenharia da } \\
\text { Produção, Filosofia, Currículo e Política Educacional, Desenvolvimento } \\
\text { Internacional, Engenharia Elétrica, Psicopedagogia, Matemática, Ciências Sociais, } \\
\text { Ecologia e Recursos Humanos, Sociologia, Economia e Música. }\end{array}$ \\
\hline $\begin{array}{l}\text { Instituição } \\
\text { Formadora } \\
\text { Doutoral }\end{array}$ & $\begin{array}{l}52 \% \text { UFC; } 23 \% \text { em instituições estrangeiras; } 5 \% \text { na USP e na UNICAMP } \\
\text { respectivamente; } 2 \% \text { na PUC/SP, UFRN e UFSCar cada uma; cada universidade } \\
\text { apresentou o percentual de } 1 \% \text {, sendo elas, a UFRGS, UFPE, UFSC, UFPB, } \\
\text { UFMG, ITA, UFRJ, IMPA e UFSM. }\end{array}$ \\
\hline $\begin{array}{l}\text { écada da } \\
\text { ormação } \\
\text { outoral }\end{array}$ & $\begin{array}{l}\text { A década de } 2000 \text { concentrou } 74 \% \text { da formação, enquanto as décadas anteriores } \\
\text { totalizaram } 26 \% \text {. }\end{array}$ \\
\hline
\end{tabular}

Fonte: Consulta ao Currículo Lattes em fevereiro/março de 2017.

Outro aspecto observado na atual proposta do programa refere-se à interface com a Educação Básica, que vem se materializando especificamente por intermédio do Programa Institucional de Bolsa de Iniciação à Docência (PIBID), projetos de extensão, oficinas e assessoramento destinados aos professores da Educação Básica para auxiliá-los no enfrentamento dos desafios e limites do contexto escolar.

No que diz respeito às produções intelectuais docentes, o quantitativo no período de 2009 a 2016 pode ser acompanhado nas tabelas 4, 5 e 6 .

Tabela 4 - Produção intelectual docente UFC - Artigos

\begin{tabular}{lccccccccc}
\hline DOCENTES & $\mathbf{2 0 0 9}$ & $\mathbf{2 0 1 0}$ & $\mathbf{2 0 1 1}$ & $\mathbf{2 0 1 2}$ & $\mathbf{2 0 1 3}$ & $\mathbf{2 0 1 4}$ & $\mathbf{2 0 1 5}$ & $\mathbf{2 0 1 6}$ & TOTAL \\
\hline Professores & 41 & 36 & 43 & 52 & 47 & 49 & 39 & 48 & 355 \\
Professoras & 20 & 35 & 29 & 51 & 43 & 45 & 33 & 46 & 302 \\
\hline
\end{tabular}

Fonte: Consulta o Currículo Lattes em fevereiro/março de 2017. 
Tabela 5 - Produção intelectual docente UFC - Livros

\begin{tabular}{lccccccccc}
\hline DOCENTES & $\mathbf{2 0 0 9}$ & $\mathbf{2 0 1 0}$ & $\mathbf{2 0 1 1}$ & $\mathbf{2 0 1 2}$ & $\mathbf{2 0 1 3}$ & $\mathbf{2 0 1 4}$ & $\mathbf{2 0 1 5}$ & $\mathbf{2 0 1 6}$ & TOTAL \\
\hline Professores & 41 & 36 & 43 & 52 & 47 & 49 & 39 & 48 & 214 \\
Professoras & 21 & 39 & 27 & 23 & 16 & 16 & 20 & 30 & 192 \\
\hline
\end{tabular}

Fonte: Consulta ao Currículo Lattes em fevereiro/março de 2017.

Tabela 6 - Produção intelectual docente UFC - Capítulos de Livro

\begin{tabular}{lccccccccc}
\hline DOCENTES & $\mathbf{2 0 0 9}$ & $\mathbf{2 0 1 0}$ & $\mathbf{2 0 1 1}$ & $\mathbf{2 0 1 2}$ & $\mathbf{2 0 1 3}$ & $\mathbf{2 0 1 4}$ & $\mathbf{2 0 1 5}$ & $\mathbf{2 0 1 6}$ & TOTAL \\
\hline Professores & 37 & 65 & 85 & 106 & 78 & 90 & 103 & 119 & 355 \\
Professoras & 42 & 68 & 58 & 76 & 92 & 103 & 130 & 116 & 685 \\
\hline
\end{tabular}

Fonte: Consulta ao Currículo Lattes em fevereiro/março de 2017.

Constatamos que, na produção de artigos e de livros, há um equilíbrio entre professoras e professores. Contudo, os docentes assumem a dianteira, com 44 publicações de artigos e 27 de livros. Verificamos, também, que na categoria capítulos de livros, o quantitativo entre professores e professoras foi representativo. No entanto, a produção feminina quase dobrou em relação à masculina, tendo em conta que, nas duas categorias docentes, o panorama foi de progressão entre 2009 a 2016, exceto no ano de 2013, para os professores, e 2011, para as professoras.

O PPGE realizou mudanças em sua estrutura curricular durante os 30 anos de atuação com vistas a atender às transformações decorrentes das políticas educacionais. Mediante o exposto, atualmente, o PPGE apresenta sua área de concentração em Educação brasileira abrangendo nove linhas de pesquisa, as quais verificaremos no Quadro 4.

Quadro 4 - Linhas de pesquisa e temáticas estudadas - UFC

\begin{tabular}{|c|c|}
\hline $\begin{array}{l}\text { Linhas de } \\
\text { pesquisa }\end{array}$ & Temáticas estudadas \\
\hline $\begin{array}{l}\text { Educação, Currículo } \\
\text { e Ensino }\end{array}$ & $\begin{array}{l}\text { Currículo, ensino, formação docente, educação, docência e escola, currículo } \\
\text { interdisciplinar e multirreferencial, linguagem e tecnologias digitais. }\end{array}$ \\
\hline $\begin{array}{l}\text { Movimentos Sociais } \\
\text { e Educação Popular }\end{array}$ & $\begin{array}{l}\text { Educações, movimentos sociais, educação popular, educação do campo, } \\
\text { educação ambiental, novos paradigmas educativos, educação e } \\
\text { espiritualidade, educação e cultura de paz, arte e educação, africanidade e } \\
\text { afrodescendência, jovens na escola, família e sociedade, etnia, cultura, } \\
\text { subjetividade e gênero. }\end{array}$ \\
\hline $\begin{array}{l}\text { História e Memória } \\
\text { da Educação }\end{array}$ & $\begin{array}{l}\text { História da educação, instituições, reformas escolares no Brasil, práticas } \\
\text { pedagógicas, políticas educacionais, história e memória. }\end{array}$ \\
\hline Trabalho e Educação & $\begin{array}{l}\text { Mundo do trabalho, formação do trabalhador, política educacional, reforma } \\
\text { do ensino médio e Ensino Superior. }\end{array}$ \\
\hline $\begin{array}{l}\text { Desenvolvimento, } \\
\text { Linguagem } \\
\begin{array}{l}\text { Educação } \\
\text { Criança }\end{array}\end{array}$ & $\begin{array}{l}\text { Educação infantil, desenvolvimento humano, linguagens, formação de } \\
\text { professores, intervenção pedagógica, diversidade, ludicidade e cultura do } \\
\text { desenvolvimento infantil, educação especial e aprendizagem. }\end{array}$ \\
\hline
\end{tabular}




\begin{tabular}{|l|l|}
\hline $\begin{array}{l}\text { Avaliação } \\
\text { Educacional }\end{array}$ & $\begin{array}{l}\text { Práticas de avaliação, avaliação da aprendizagem, avaliação de instituiçães } \\
\text { escolares, avaliação de políticas públicas, modelos em avaliação, } \\
\text { instrumentos de medidas, procedimentos de avaliação e políticas sociais. }\end{array}$ \\
\hline $\begin{array}{l}\text { Filosofia e Sociologia } \\
\text { da Educação }\end{array}$ & $\begin{array}{l}\text { Economia, política crítica, educação, sociabilidade, materialismo histórico, } \\
\text { dialética, filosofias da diferença, antropologia e educação, biopolítica dos } \\
\text { indivíduos e coletividades, o marxismo, neo-marxistas, filosofia política e à } \\
\text { educação. }\end{array}$ \\
\hline $\begin{array}{l}\text { Pesquisas em em } \\
\text { História da Educação } \\
\text { Comparada }\end{array}$ & $\begin{array}{l}\text { História da educação; práticas educativas; família, sexualidade e educação; } \\
\text { perspectiva psicossocial, genealógica, cultural, internacional e } \\
\text { contemporânea; influência Sociológica da psicologia e da antropologia. }\end{array}$ \\
\hline $\begin{array}{l}\text { Marxismo, Educação } \\
\text { e Luta de Classes }\end{array}$ & $\begin{array}{l}\text { Relação teoria-prática, socialismo, luta dos trabalhadores, ontologia } \\
\text { marxiana e educação, crise do capital, instrumentos internacionais da } \\
\text { educação, sociedade capitalista, educação emancipadora, formação } \\
\text { docente. }\end{array}$ \\
\hline
\end{tabular}

Fonte: Consulta a proposta do programa no período de fevereiro/março de 2017.

\section{PROGRAMA DE PÓS-GRADUAÇÃO EM EDUCAÇÃO DA UFPE}

O Programa de Pós-Graduação em Educação da Universidade Federal de Pernambuco teve sua aprovação em 1978 vinculada à Faculdade de Pernambuco, com a primeira turma de Mestrado. Após 24 anos da aprovação do Mestrado, em 2002, o programa implanta o curso de Doutorado. No decorrer dos anos, o programa reformulou sua proposta curricular a fim de atender os princípios da coerência temática e consistência interna, bem como um referencial teórico consistente.

Além das turmas de Mestrado e Doutorado na modalidade regular, o programa também oferta a modalidade Minter e Dinter, parceria firmada em 2017 com o Instituto Federal de Pernambuco (IFPE). Em relação à interlocução desta instituição com a Educação Básica, podemos constatar um papel relevante deste programa com a formação continuada dos professores da Escola Básica, pois a parceria firmada entre a Universidade e as Secretarias Municipal e Estadual tem fortalecido as ações entre esses dois níveis de ensino, seja por meio do assessoramento em programas adotados pelas redes como Programa Nacional de Alfabetização na Idade Certa (PNAIC), Programa Nacional de Bibliotecas nas Escolas entre outros, seja na elaboração de materiais pedagógicos ou na oferta de cursos em especialização e projetos de extensão.

A avaliação do programa apresenta-se de forma positiva por duas razões. A primeira delas refere-se a que é feita pela comunidade acadêmica, a qual tem avaliado de forma positiva as ações deste programa, o que tem refletido, consequentemente, no aumento da demanda. A segunda perspectiva é a Avaliação da CAPES, uma vez que o programa vem se mantendo com nota cinco nas últimas 
avaliações - Avaliação Trienal 2013 e Avaliação Quadrienal 2017. Outro foco de nossa investigação se deu com o corpo docente do programa, no qual foi possível criar um perfil da formação desses profissionais, conforme exposto no Quadro 5.

Quadro 5 - Perfil da Formação Docente UFPE

\begin{tabular}{|c|c|}
\hline № Docente & 49 doutores, sendo 29 mulheres e 20 homens. \\
\hline $\begin{array}{l}\text { Formação } \\
\text { Inicial }\end{array}$ & $\begin{array}{l}\text { Com formação em Pedagogia são } 17 \text { docentes e } 32 \text { nas demais formações, distribuídas } \\
\text { em Filosofia, História, Educação Física, Matemática, Economia, Ciências Sociais, Biologia, } \\
\text { Fonoaudiologia, Licenciatura em Música, Letras, Licenciatura em Ciências e uma } \\
\text { professora sem informação no Lattes. }\end{array}$ \\
\hline $\begin{array}{l}\text { Formação } \\
\text { Doutoral }\end{array}$ & $\begin{array}{l}\text { Em Educação o percentual de docentes chega 52,9\%. As demais áreas totalizaram 47,1\%, } \\
\text { distribuídos nas áreas de História, Psicologia, Sociologia, Ciências Sociais, Música, } \\
\text { Educação Física, Linguística, Letras, Psicologia e Ciência do Deporto. }\end{array}$ \\
\hline $\begin{array}{l}\text { Instituição } \\
\text { Formadora } \\
\text { Doutoral }\end{array}$ & $\begin{array}{l}\text { Com } 44,8 \% \text { ficou a UFPE; } 30,6 \% \text { instituições estrangeiras; a USP, UNIME, UFRGS, UFM } \\
\text { e UFF atingiram } 2,05 \% \text { cada uma; a UFB e a UFRN ficaram com } 4,08 \% \text {; a UNICAMP com } \\
6,1 \% \text {. }\end{array}$ \\
\hline $\begin{array}{l}\text { Década da } \\
\text { Formação } \\
\text { Doutoral }\end{array}$ & $65,3 \%$ da formação se concentrou na década de 2000 e 34,7\% nas décadas anteriores. \\
\hline
\end{tabular}

Fonte: Consulta ao Currículo Lattes em fevereiro/março de 2017.

No que tange à produção intelectual docente, os resultados estão disponíveis nas tabelas 7, 8 e 9 .

Tabela 7 - Produção intelectual docente UFPE - Artigos

\begin{tabular}{lccccccccc}
\hline DOCENTES & $\mathbf{2 0 0 9}$ & $\mathbf{2 0 1 0}$ & $\mathbf{2 0 1 1}$ & $\mathbf{2 0 1 2}$ & $\mathbf{2 0 1 3}$ & $\mathbf{2 0 1 4}$ & $\mathbf{2 0 1 5}$ & $\mathbf{2 0 1 6}$ & TOTAL \\
\hline Professores & 21 & 25 & 25 & 27 & 34 & 38 & 30 & 29 & 229 \\
Professoras & 30 & 45 & 38 & 55 & 57 & 55 & 50 & 52 & 382 \\
\hline
\end{tabular}

Fonte: Consulta ao Currículo Lattes em fevereiro/março de 2017.

Tabela 8 - Produção intelectual docente UFPE - Livros

\begin{tabular}{lccccccccc}
\hline DOCENTES & $\mathbf{2 0 0 9}$ & $\mathbf{2 0 1 0}$ & $\mathbf{2 0 1 1}$ & $\mathbf{2 0 1 2}$ & $\mathbf{2 0 1 3}$ & $\mathbf{2 0 1 4}$ & $\mathbf{2 0 1 5}$ & $\mathbf{2 0 1 6}$ & TOTAL \\
\hline Professores & 8 & 11 & 16 & 18 & 12 & 12 & 7 & 5 & 89 \\
Professoras & 7 & 11 & 3 & 7 & 13 & 7 & 8 & 13 & 69 \\
\hline
\end{tabular}

Fonte: Consulta ao Currículo Lattes em fevereiro/março de 2017.

Tabela 9 - Produção intelectual docente UFPE - Capítulos de livro

\begin{tabular}{lccccccccc}
\hline DOCENTES & $\mathbf{2 0 0 9}$ & $\mathbf{2 0 1 0}$ & $\mathbf{2 0 1 1}$ & $\mathbf{2 0 1 2}$ & $\mathbf{2 0 1 3}$ & $\mathbf{2 0 1 4}$ & $\mathbf{2 0 1 5}$ & $\mathbf{2 0 1 6}$ & TOTAL \\
\hline Professores & 24 & 36 & 38 & 53 & 29 & 17 & 21 & 25 & 243 \\
Professoras & 29 & 60 & 42 & 72 & 50 & 43 & 30 & 39 & 365 \\
\hline
\end{tabular}

Fonte: Consulta ao Currículo Lattes em fevereiro/março de 2017.

Por um lado, observamos que as publicações de artigos apresentam um número significativo e progressivo entre os docentes, haja vista que, entre os anos 
de 2015 a 2016, a produção docente exibe uma redução de, apenas, um artigo em média. Em contrapartida, as professoras assumem a liderança nesse cenário, com um total de aproximadamente 29 artigos publicados por ano.

Por outro lado, a publicação de livros assume o menor número de produção dos docentes. Entretanto, na categoria livros, os professores respondem à chamada. Podemos observar, em relação à publicação de livros, uma oscilação no resultado das professoras, variando de três a treze publicações por ano. A despeito do volume de capítulos de livro, as professoras retomam a liderança e atingem o maior número de produções em 2012, com 70 capítulos, apresentando, assim, uma regularidade na produção no período de 2009 a 2016. Notamos, também, que a produção de professores apresentou um significativo volume de capítulos de livro, atingindo a máxima de 53 publicações em 2012.

Atualmente, a área de concentração do programa está voltada para a Educação e vincula-se a mesma seis linhas de pesquisas, sendo elas: Educação e Espiritualidade, Educação e Linguagem, Formação de Professores e Prática Pedagógica, Política Educacional, Planejamento e Gestão da Educação, Teoria e História da Educação, Subjetividades Coletivas, Movimentos Sociais e Educação Popular. Apresentaremos na sequencia a descrição de cada linha de pesquisa.

\section{Quadro 6 - Linhas de pesquisa e temáticas estudadas - UFPE}

\begin{tabular}{|c|c|}
\hline Linhas de pesquisa & Temáticas estudadas \\
\hline $\begin{array}{ll}\text { Educação } & \text { e } \\
\text { Espiritualidade } & \end{array}$ & $\begin{array}{l}\text { Formação humana, filosofia e espiritualidade, filosofia budista, teoria } \\
\text { budista, noção espiritual self. }\end{array}$ \\
\hline $\begin{array}{l}\text { Educação } \\
\text { Linguagem }\end{array}$ & $\begin{array}{l}\text { Práticas de alfabetização e letramento, ensino e aprendizagem da língua } \\
\text { portuguesa, formação inicial e continuada da docência, história das } \\
\text { práticas de leitura, produção textual, recursos didáticos. }\end{array}$ \\
\hline $\begin{array}{lr}\text { Formação } & \text { de } \\
\text { Professores e } & \text { Prática } \\
\text { Pedagógica } & \end{array}$ & $\begin{array}{l}\text { Práticas educacionais, processos de formação } \\
\text { profissionalização e trabalho docente, currículo e cultura, educação e } \\
\text { etnias, educação de jovens e adultos e gênero. }\end{array}$ \\
\hline $\begin{array}{l}\text { Política Educacional, } \\
\text { Planejamento e } \\
\text { Gestão da Educação }\end{array}$ & $\begin{array}{l}\text { Gestão, política educacional, planejamento, gestão escolar, avaliação de } \\
\text { programas e projetos. }\end{array}$ \\
\hline $\begin{array}{l}\text { Teoria e História da } \\
\text { Educação }\end{array}$ & $\begin{array}{l}\text { Teoria da educação, história da leitura, história da educação, } \\
\text { individualidade e formação, pesquisa em teoria e história. }\end{array}$ \\
\hline $\begin{array}{l}\text { Subjetividades } \\
\text { coletivas, movimentos } \\
\text { sociais e educação } \\
\text { popular. }\end{array}$ & Cultura, identidades coletivas, subjetividades. \\
\hline
\end{tabular}

Fonte: Consulta a proposta do programa no período de fevereiro/março de 2017. 


\section{PROGRAMA DE PÓS-GRADUAÇÃO EM EDUCAÇÃO DA UFRN}

No ano de 1977, a Faculdade de Educação da Universidade Federal do Rio Grande do Norte criou o primeiro curso de Mestrado em Educação, com área de concentração em Educação, e, em 1993, após 16 anos, inaugurou-se o curso de Doutorado na referida universidade. Ao longo do tempo, o Programa passou por várias reestruturações com a finalidade de adequar o seu funcionamento aos padrões da CAPES (CAPES, 2017). Além da oferta de Mestrado e Doutorado, o programa estabeleceu parceria com a Universidade Federal do Maranhão, Instituto Federal de Educação, Ciência e Tecnologia e Universidade Estadual do Sudoeste da Bahia por meio do Programa de Cooperação Acadêmica (PROCAD) para a oferta da Dinter e Minter.

No que se refere à intersecção com a Educação Básica, o programa define como objetivo central de sua proposta a formação dos professores para atuarem na Educação Básica e no Ensino Superior. Além desse eixo norteador do programa, constatamos que a maior demanda dos discentes ingressantes no programa é professor ou professora atuante na Educação Básica e na Secretaria de Educação do Estado de Pernambuco. De acordo com a proposta do programa, este perfil de discente contribui fortemente para que estes profissionais atuem exitosamente no setor público qualificando e consolidando a educação pública do país.

Além desse perfil discente, o programa atua na oferta de formação de professores por meio do trabalho com o PIBID, em projetos de extensão relacionados à Leitura e Escrita e na articulação, especialmente, com o estágio docente dos mestrandos e doutorandos do programa colaborando, assim, com os docentes em disciplinas de graduação, na condição de partícipes coadjuvantes, em disciplinas de seu interesse ou junto do seu professor orientador (CAPES, 2017).

Do ponto de vista da avaliação da CAPES, o programa alcançou nota cinco na Avaliação Quadrienal 2017, ou seja, a nota aumentou em um ponto a mais em relação à Avaliação Trienal 2013, reflexo das ações desenvolvidas pelo programa no âmbito da pesquisa, do ensino e da extensão, especificamente, no tocante à produção intelectual que se constitui como uma das principais regras do campo para alcançar a qualidade do programa.

Ressaltamos, ainda, o perfil dos docentes que compõem o quadro de professores do programa. Os indicadores estão explícitos no Quadro 7. 
Quadro 7 - Perfil da formação docente UFRN

\begin{tabular}{|l|l|}
\hline $\begin{array}{l}\text { No } \\
\text { Docente }\end{array}$ & 56 doutores, sendo 39 mulheres e 17 homens. \\
\hline $\begin{array}{l}\text { Formação } \\
\text { Inicial }\end{array}$ & $\begin{array}{l}23 \text { professores com formação em Pedagogia e } 30 \text { estiveram entre diferentes áreas: } \\
\text { História, Ciências Sociais, Física, Filosofia, Matemática, Tecnologia em Matemática, } \\
\text { Educação Básica, Engenharia Elétrica, Psicologia, Licenciatura em Ciências, } \\
\text { Química, Educação Física, Letras, Sociologia e Política, Comunicação Social e } \\
\text { Biologia. }\end{array}$ \\
\hline $\begin{array}{l}\text { Formação } \\
\text { Doutoral }\end{array}$ & $\begin{array}{l}\text { Educação assumiu a dianteira, com 75,47\%. Matemática, Educação Física, Ciências } \\
\text { Sociais, História, Sociologia e Linguística somaram 24,53\%. }\end{array}$ \\
\hline $\begin{array}{l}\text { Instituição } \\
\begin{array}{l}\text { Formadora } \\
\text { Doutoral }\end{array}\end{array}$ & $\begin{array}{l}\text { UFRN com 43,5\%; UFC e PUC com 3,9\% respectivamente; USP com 11,4\%; as } \\
\text { instituições estrangeiras com 20,2\%; UNICAMP com 5,7\% e UDF, UFPB, UFF, }\end{array}$ \\
\hline $\begin{array}{l}\text { Década da } \\
\text { Formaçãa, UNIMEP e UFMG com 1,9\% cada uma. } \\
\text { Doutoral }\end{array}$ & $\begin{array}{l}\text { Década de 2000 com um percentual de 53\%, enquanto as demais formações } \\
\text { ocorrem nas décadas anteriores, somando um total de 47\%. }\end{array}$ \\
\hline
\end{tabular}

Fonte: Consulta ao Currículo Lattes em fevereiro/março de 2017.

Observamos a predominância de professoras na composição do quadro de professores do programa. Notamos também quanto à formação destes profissionais que há uma variação na formação inicial e continuada da área de conhecimento com predominância para os cursos voltados para o campo da educação. Os resultados da produção intelectual docente podem ser visualizados nas tabelas 10, 11 e 12.

Tabela 10 - Produção intelectual docente UFRN - Artigos

\begin{tabular}{lccccccccc}
\hline DOCENTES & $\mathbf{2 0 0 9}$ & $\mathbf{2 0 1 0}$ & $\mathbf{2 0 1 1}$ & $\mathbf{2 0 1 2}$ & $\mathbf{2 0 1 3}$ & $\mathbf{2 0 1 4}$ & $\mathbf{2 0 1 5}$ & $\mathbf{2 0 1 6}$ & TOTAL \\
\hline Professores & 21 & 27 & 25 & 29 & 34 & 39 & 31 & 29 & 235 \\
\hline Professoras & $\mathbf{2 9}$ & $\mathbf{4 3}$ & $\mathbf{3 7}$ & $\mathbf{5 3}$ & $\mathbf{5 4}$ & $\mathbf{4 7}$ & $\mathbf{4 3}$ & $\mathbf{4 7}$ & 354 \\
\hline \multicolumn{7}{r}{ Fonte: Consulta ao Currículo Lattes em fevereiro/março de 2017 } \\
\hline
\end{tabular}

Tabela 11 - Produção intelectual docente UFRN - Livros

\begin{tabular}{cccccccccc}
\hline DOCENTES & $\mathbf{2 0 0 9}$ & $\mathbf{2 0 1 0}$ & $\mathbf{2 0 1 1}$ & $\mathbf{2 0 1 2}$ & $\mathbf{2 0 1 3}$ & $\mathbf{2 0 1 4}$ & $\mathbf{2 0 1 5}$ & $\mathbf{2 0 1 6}$ & TOTAL \\
\hline Professores & 8 & 11 & 17 & 18 & 12 & 13 & 7 & 5 & 91 \\
Professoras & 7 & 10 & 3 & 7 & 13 & 7 & 7 & 13 & 67 \\
\hline
\end{tabular}

Fonte: Consulta ao Currículo Lattes em fevereiro/março de 2017.

Tabela 12 - Produção intelectual docente UFRN - Capítulos de livro

\begin{tabular}{lccccccccc}
\hline DOCENTES & $\mathbf{2 0 0 9}$ & $\mathbf{2 0 1 0}$ & $\mathbf{2 0 1 1}$ & $\mathbf{2 0 1 2}$ & $\mathbf{2 0 1 3}$ & $\mathbf{2 0 1 4}$ & $\mathbf{2 0 1 5}$ & $\mathbf{2 0 1 6}$ & TOTAL \\
\hline Professores & 24 & 39 & 39 & 56 & 29 & 19 & 21 & 26 & 253 \\
Professoras & 29 & 57 & 41 & 70 & 49 & 43 & 27 & 37 & 353 \\
\hline
\end{tabular}

Fonte: Consulta ao Currículo Lattes em fevereiro/março de 2017. 
Constatamos que a produção de artigos a partir dos dados dispostos na Tabela 10, 11 e 12 apresentou um expressivo progresso entre professores e professoras. Contudo, a produção das professoras assume a liderança em quantidade de publicação. Na produção de livros, os professores apresentam um volume progressivo de publicações entre 2009 e 2012. A partir de 2013, este número decresce. Quanto à produção das professoras, o número de publicações de livros variou no período pesquisado, apresentando entre três e treze publicações por ano.

A área de concentração do programa não sofreu alteração desde sua existência. As linhas de pesquisas sofreram mudanças com vista ao atendimento das demandas. Atualmente, consta no programa o total de sete linhas definidas conforme o Quadro 8.

Quadro 8 - Linhas de pesquisa e temáticas estudadas - UFRN

\begin{tabular}{|c|c|}
\hline $\begin{array}{l}\text { Linhas de } \\
\text { pesquisa }\end{array}$ & Temáticas estudadas \\
\hline $\begin{array}{l}\text { Educação, } \\
\text { Comunicação, } \\
\text { Linguagens } \\
\text { Movimento }\end{array}$ & $\begin{array}{l}\text { Leitura e literatura, linguagens, corpo, estética, movimento } \\
\text { humano, expressividade e filosofias do corpo, cultura de } \\
\text { movimento, inclusão, educação física escolar, saúde e sociedade, } \\
\text { meios de comunicação. }\end{array}$ \\
\hline $\begin{array}{l}\text { Educação, } \\
\text { Construção das } \\
\text { Ciências e } \\
\text { Educativas }\end{array}$ & $\begin{array}{l}\text { Ciências e processos formativos, ciências e as práticas sociais, } \\
\text { nas abordagens da matemática, das ciências naturais, das } \\
\text { linguagens, ciência e tradição, formação de professores, } \\
\text { programas escolares, currículos, ciências naturais e educação do } \\
\text { campo, matemática e língua portuguesa, formação docente, } \\
\text { políticas públicas, linguagens e educação. }\end{array}$ \\
\hline $\begin{array}{l}\text { Educação, } \\
\text { Formação } \\
\text { Profissionalização } \\
\text { Docente }\end{array}$ & $\begin{array}{l}\text { Agentes educacionais e as práticas, desenvolvimento profissional, } \\
\text { profissionalização docente, a comunicação, os processos } \\
\text { psicossociais, processos socioculturais do conhecimento, } \\
\text { educação escolar, aprendizagem, formação da docência, os } \\
\text { sistemas socioculturais, socialização e educação na escola, } \\
\text { identidade e representações socias na educação, aprendizagem } \\
\text { no ensino médio e superior, identidade profissional, sociogênese } \\
\text { das representações sociais, teoria moscoviciana. }\end{array}$ \\
\hline $\begin{array}{l}\text { Educação, Estudos } \\
\text { Sócio histórico e } \\
\text { Filosóficos }\end{array}$ & $\begin{array}{l}\text { Fundamentos históricos, filosóficos e sociopolíticos da educação, } \\
\text { práticas educativas, ensino de história, docência, literatura e } \\
\text { gênero, história do livro didático e da alfabetização, com foco na } \\
\text { formação de uma sociedade. }\end{array}$ \\
\hline $\begin{array}{l}\text { Educação, Política e } \\
\text { Práxis Educativas: }\end{array}$ & $\begin{array}{l}\text { Políticas de educação, educação e e trabalho, gestão } \\
\text { financiamento, políticas de formação de professores e gestores. }\end{array}$ \\
\hline $\begin{array}{l}\text { Educação, Currículo } \\
\text { e Práticas } \\
\text { Pedagógicas }\end{array}$ & $\begin{array}{l}\text { Cultura e educação, construção de conhecimentos, saberes em } \\
\text { diferentes contextos, práticas pedagógicas e curriculares, jovens e } \\
\text { adultos, formação inicial e continuada da educação. }\end{array}$ \\
\hline $\begin{array}{l}\text { Educação e Inclusão } \\
\text { em Contextos } \\
\text { Educacionais }\end{array}$ & $\begin{array}{l}\text { Educação inclusiva, políticas, formação docente, práticas } \\
\text { pedagógicas e artísticas. }\end{array}$ \\
\hline
\end{tabular}

Fonte: Consulta a proposta do programa no período de fevereiro a março de 2017. 


\section{PROGRAMA DE PÓS-GRADUAÇÃO EM EDUCAÇÃO DA UFRPE}

O programa de Pós-Graduação em Educação, Cultura e Identidades da Universidade Federal Rural de Pernambuco, aprovado em 2013, deu início às suas atividades em 2014 com a oferta da primeira turma de Mestrado do programa. Tratase de um programa associado com a Fundação João Nabuco (FUNDAJ) que resultou da parceria entre a Fundação e a Universidade desde 2007.

Esta parceria apresenta resultados positivos para o campo educacional em razão das ações interinstitucionais e acadêmicas que as instituições vêm realizando ao longo do tempo no sentido de fortalecer a Pós-Graduação em Pernambuco, como também a discussão das Relações Étnico-Raciais (CAPES, 2017). Tal discussão se constitui um dos principais eixos norteadores das ações do programa para o enfrentamento das desigualdades sociais de jovens no Brasil, mas, com especial atenção para a questão de raça e classe social.

A inserção do programa no Sistema Nacional de Pós-Graduação é recente. Porém, a parceria entre a UFRPE e a FUNDAJ já data de longos anos, com trabalho em conjunto por meio da oferta de cursos, eventos e formações em nível lato sensu realizado a partir de 2007. Essas interlocuções contribuem no fortalecimento das ações do PPGECl como o intercâmbio com as universidades francesas, a organização de eventos regionais e nacionais, assim como a oferta de formação continuada para todo o estado de Pernambuco por meio de diferentes parcerias.

Atualmente, o programa recebeu nota três da Avaliação Quadrienal 2017 da CAPES e vem estabelecendo metas, diretrizes e ações para melhorar a qualidade do programa. Dentre estas ações desenvolvidas pelo programa destacamos a proposta curricular numa perspectiva interdisciplinar, a parceria com os grupos de pesquisas, especialmente os NEAB's, a ampliação da formação no estado de Pernambuco especificamente para os professores da Educação Básica, além de ações que favoreçam um maior impacto social.

A interlocução com a Educação Básica vem se materializando por meio da coordenação de professores na Universidade Federal Rural de Pernambuco e na Fundação Joaquim Nabuco, do Comitê do Programa Gestor Institucional da Rede Nacional de Formação Inicial e Continuada de Professores da Educação Básica RENAFORM. 
Além disso, vários docentes coordenam cursos de extensão, aperfeiçoamento e especialização de professores da Educação Básica vinculados ao RENAFORM (CAPES, 2017). Outro aspecto observado na investigação diz respeito ao perfil da formação docente dos professores que fazem parte do programa, apresentado no Quadro 9.

Quadro 9 - Perfil da formação docente - UFRPE

\begin{tabular}{|l|l|}
\hline $\begin{array}{l}\text { No } \\
\text { Docente }\end{array}$ & $\mathbf{1 5}$ doutores, assim constituídos: $\mathbf{4}$ professores e 11 professoras \\
\hline $\begin{array}{l}\text { Formação } \\
\text { Inicial }\end{array}$ & $\begin{array}{l}\text { Direito, Psicologia, Ciências Sociais, História, Psicologia, Filosofia, Letras, Ciências } \\
\text { Biomédicas, Pedagogia e Ciências Biológicas. }\end{array}$ \\
\hline $\begin{array}{l}\text { Formação } \\
\text { Doutoral }\end{array}$ & $\begin{array}{l}\text { Educação com um percentual de 40\%. As áreas de Filosofia, Psicologia, Direito, } \\
\text { Sociologia, Ciências Sociais e História totalizaram } 60 \% \text { da formação doutoral. }\end{array}$ \\
\hline $\begin{array}{l}\text { Instituição } \\
\begin{array}{l}\text { Formadora } \\
\text { Doutoral }\end{array}\end{array}$ & $\begin{array}{l}\text { A UFPE com } 67 \% \text { e com } 6,6 \% \text { ficaram a PUC/SP, USP/SP, UMA, UFRN e a } \\
\text { instituição estrangeira, cada uma. }\end{array}$ \\
\hline $\begin{array}{l}\text { Década da } \\
\text { Formação } \\
\text { Doutoral }\end{array}$ & $80 \%$ com formação na década de 2000 e $20 \%$ nas décadas anteriores. \\
\hline
\end{tabular}

Fonte: Consulta ao Currículo Lattes em fevereiro/março de 2017.

Diferentemente dos programas apresentados anteriormente, a formação inicial do corpo docente apresenta uma diversidade entre as áreas de conhecimento, sem predominância de uma área específica. Em relação à formação doutoral, prevaleceu à área da educação com o percentual de $40 \%$.

Em relação à produção intelectual do corpo docente, observamos que a publicação de artigos apresenta uma significativa diferença entre os docentes. As professoras publicam em média 13 artigos por ano, e os professores, dois artigos. Em relação à produção de livros, inferimos que a publicação não acontece com frequência. Ainda assim, as professoras assumem a liderança com média de três publicações por ano, exceto o ano de 2009 , em que as docentes não realizaram nenhuma publicação. Quanto aos professores, as publicações ocorreram nos anos de 2012, 2014 e 2016. Em relação à produção de capítulos de livro, a média de publicação das professoras chega a 11 livros, enquanto a dos professores, cinco livros. A área de concentração Educação é composta por três linhas de pesquisa, conforme exposto no Quadro 10. 
Quadro 10 - Linhas de pesquisa e temáticas estudadas - UFRPE

\begin{tabular}{|c|c|}
\hline Linhas de pesquisa & Temáticas estudadas \\
\hline $\begin{array}{lr}\text { Movimentos } & \text { Sociais, } \\
\text { Práticas } & \text { Educativo- } \\
\text { Culturais } & \text { e } \\
\text { ldentidades } & \end{array}$ & $\begin{array}{l}\text { Processos educativos e culturais, movimentos sociais, identidades } \\
\text { étnico-raciais, gênero, sexualidade, juventudes, educação e } \\
\text { diversidade cultural, história da formação sociocultural brasileira, } \\
\text { identidades, educação, movimentos sociais e relações étnico- } \\
\text { raciais. }\end{array}$ \\
\hline $\begin{array}{l}\text { Desenvolvimento e } \\
\text { Processos } \\
\text { Educacionais e } \\
\text { Culturais da Infância e } \\
\text { da Juventude }\end{array}$ & $\begin{array}{l}\text { Processos cognitivos, afetivos, tecnológicos, comunicacionais e } \\
\text { culturais, relativos ao desenvolvimento humano, aprendizagens, } \\
\text { infância, juventude, políticas de atendimento à infância e à } \\
\text { juventude, cognição, processos midiáticos e identidades. }\end{array}$ \\
\hline $\begin{array}{l}\text { Políticas, Programas e } \\
\text { Gestão de Processos } \\
\text { Educacionais e } \\
\text { Culturais }\end{array}$ & $\begin{array}{l}\text { Políticas, programas educacionais e culturais, reformas, a gestão e } \\
\text { práticas educativas e culturais. }\end{array}$ \\
\hline
\end{tabular}

Fonte: Consulta a proposta do Programa no período de fevereiro a março de 2017.

Tabela 13 - Produção intelectual docente UFRPE - Artigos

\begin{tabular}{lccccccccc}
\hline DOCENTES & $\mathbf{2 0 0 9}$ & $\mathbf{2 0 1 0}$ & $\mathbf{2 0 1 1}$ & $\mathbf{2 0 1 2}$ & $\mathbf{2 0 1 3}$ & $\mathbf{2 0 1 4}$ & $\mathbf{2 0 1 5}$ & $\mathbf{2 0 1 6}$ & TOTAL \\
\hline Professores & - & 5 & 1 & 1 & 2 & 4 & 4 & 1 & 18 \\
Professoras & 8 & 15 & 19 & 13 & 15 & 7 & 14 & 12 & 103 \\
\hline
\end{tabular}

Fonte: Consulta ao Currículo Lattes em fevereiro/março de 2017.

Tabela 14 - Produção intelectual docente UFRPE - Livros

\begin{tabular}{lccccccccc}
\hline DOCENTES & 2009 & $\mathbf{2 0 1 0}$ & $\mathbf{2 0 1 1}$ & $\mathbf{2 0 1 2}$ & $\mathbf{2 0 1 3}$ & $\mathbf{2 0 1 4}$ & $\mathbf{2 0 1 5}$ & $\mathbf{2 0 1 6}$ & TOTAL \\
\hline Professores & - & - & - & 1 & - & 4 & - & 2 & 7 \\
Professoras & - & 3 & 2 & 4 & 2 & 6 & 1 & 4 & 22 \\
\hline
\end{tabular}

Fonte: Consulta ao Currículo Lattes em fevereiro/março de 2017.

Tabela 15 - Produção intelectual docente UFRPE - Capítulos de Livro

\begin{tabular}{lccccccccc}
\hline DOCENTES & 2009 & $\mathbf{2 0 1 0}$ & $\mathbf{2 0 1 1}$ & $\mathbf{2 0 1 2}$ & $\mathbf{2 0 1 3}$ & $\mathbf{2 0 1 4}$ & $\mathbf{2 0 1 5}$ & $\mathbf{2 0 1 6}$ & TOTAL \\
\hline Professores & 1 & 1 & 2 & 5 & 3 & 3 & - & 11 & 36 \\
Professoras & 7 & 7 & 10 & 8 & 13 & 7 & 15 & 19 & 86 \\
\hline
\end{tabular}

Fonte: Consulta ao Currículo Lattes em fevereiro/março de 2017.

\section{CONSIDERAÇÕES FINAIS}

A investigação em torno da estrutura e organização dos PPGE's da região nordeste evidencia que os referidos programas, ao longo de sua institucionalização, procuraram adequar-se às recomendações da CAPES para expandir a oferta de 
cursos de Mestrado e Doutorado, a fim de garantir a formação qualificada de professores e pesquisadores para a região.

Notamos tal resultado na análise do perfil docente quanto à formação em nível doutoral desses profissionais, que tiveram, em sua maioria, as universidades que hoje atuam como instituições formadoras. Essa formação aconteceu em um número representativo na década de 2000, período em que os PPGE's na região Nordeste começavam a se destacar pelos resultados alcançados na avalição e pela qualificação do seu perfil (BALBACHEVSKY, 2005, p. 79).

O estudo permitiu observar, também, a abrangência de linhas de pesquisa nos programas em tela, que representa a possibilidade dos PPGE's em oferecer uma variedade de temas à sociedade, bem como possibilitar um trabalho interdisciplinar (WASSEN; PEREIRA; BALZAN, 2015). Essas linhas, quando bem definidas e articuladas de forma coerente com os projetos de pesquisa e a produção intelectual docente, representam um ganho para os programas, porquanto essa é uma das condições necessárias para a excelência na qualidade dos PPGE's. De acordo com Silva (2008, p. 42),

\begin{abstract}
Um dos critérios para avaliação da excelência da produção é a sua vinculação com as necessidades e anseios dos segmentos que compõem a sociedade, bem como suas repercussões na vida social. Assim, uma produção é considerada de qualidade se oferecer apoio consistente para a solução de problemas sociais, econômicos, políticos, tecnológicos, se desenvolver reflexões e mostrar disposição para participar da garantia de direitos, superação de desigualdades, respeito à valorização das diferenças étnico-raciais, combate a discriminações a pessoas e grupos.
\end{abstract}

Nesse sentido, entendemos que os PPGE's da região Nordeste estão caminhando para a excelência, haja vista que os dados apontam que, dos cinco programas analisados, quatro apresentam em suas linhas de pesquisa a discussão acerca das relações étnico-raciais, o que representa um avanço importante para o campo. Outro aspecto observado na produção intelectual foi a presença de temas relacionados à diversidade em um contexto maior como questões de gênero, identidades, sexualidade, movimentos sociais, entre outros, que buscam, como afirma Silva (2008), atender aos problemas da sociedade cumprindo com sua finalidade do compromisso da vida social.

A presença de conteúdos e processos formativos atinentes às relações étnico-raciais na proposta da maioria dos programas representa um esforço de romper com as universidades que pregam homogeneidade e superioridade de 
conhecimentos produzidos na Europa e nos Estados Unidos, que expurga a presença e a memória de conhecimentos de outras raízes constitutivas de nossa sociedade (BRASIL, 2004). Tais processos representam, também, professores mais conscientes da situação da população negra no país e, consequentemente, mais qualificados para o enfrentamento das questões voltadas para as relações étnicoraciais no âmbito escolar e acadêmico.

Esse cenário tem contribuído veementemente para o avanço na implantação e implementação de políticas públicas de combate às desigualdades raciais no ensino superior alterando o habitus desses agentes no tocante o acesso e a permanência da população negra nas universidades públicas. Entretanto, entendemos que, para potencializar as atuais políticas públicas, faz-se necessária a incorporação de um habitus de enfrentamento das desigualdades nos agentes pertencentes a esses campos, uma vez que eles são capazes de constituir um princípio gerador de práticas capazes de transformar a estrutura de um campo (BOURDIEU, 2005).

Os dados revelaram que a produção intelectual docente na região Nordeste vem sendo alvo de investimentos por parte dos pesquisadores da região. Constatamos tal afirmação não somente pelo quantitativo de produção levantada no período de 2009 a 2016, mas pela frequência na publicação das obras, que, consequentemente, geram um capital científico capaz de agregar outros tipos de capital advindos desses investimos. Dentre os quais, podemos destacar: a participação das universidades da região Nordeste nos rankings internacionais, a permanência ou o aumento das notas dos cursos na avaliação Quadrienal da CAPES, cujo resultado é advindo de acúmulo de capital científico e social do coletivo de agentes que constituem o programa, a formação humana em níveis qualificáveis, o desenvolvimento tecnológico e científico da sociedade brasileira, entre outros.

Em relação à formação docente, averiguamos que, embora boa parte dos docentes tenha formação inicial em Pedagogia e formação doutoral em Educação, há, em contrapartida, uma variação e um número representativo de profissionais que não possuem formação pedagógica para atuação no magistério, condição sine qua non da profissão docente (LORENÇO, LIMA, NARCISO, 2016). Isto porque "ser docente no Ensino Superior não é apenas uma questão de domínio de conhecimento, mas uma prática que demanda um processo formativo para tal" (CÔRREA; RIBEIRO, 2013, p. 01). 
Diante do exposto, inferimos que os PPGE's da região nordeste muito tem avançado quando a discussão trata-se da temática racial no espaço acadêmico por meio de suas linhas de pesquisas e de suas respectivas produções, pois esses avanços tem se tornado um "mecanismo de combate às práticas discriminatórias e preconceituosas na sociedade pela possibilidade de abertura da discussão nos espaços educativos, de problematizar e criar possibilidades para novas discussões" (VALENTIN; PINHO; GOMES, 2012). Acreditamos que o fortalecimento dessas ações no espaço acadêmico é indício de que novos habitus estão sendo construídos em favor de uma universidade e uma sociedade mais justa! 


\section{REFERÊNCIAS}

BALBACHEVSKY, E. A Pós-Graduação no Brasil: novos desafios para uma política bem-sucedida. In. BROCK. C.; SCHWARTZMAN, S. Os desafios da educação no Brasil. 1 ed. Rio de Janeiro: Editora Nova Fronteira, 2005.

BARDIN, L. Análise do conteúdo. 6. ed. Lisboa: Edições 70, 2011.

BOURDIEU, P. Método científico e hierarquia social dos objetos. In: NOGUEIRA, M. A.; CATANAI, A. (Org.). Escritos de educação. 9. ed. Petrópolis, RJ: Vozes, 2007, p. 33-38.

A economia das trocas simbólicas. Tradução Miceli Sérgio. 6. ed. São Paulo: Perspectiva, 2005.

BRASIL. Plano Nacional de Pós-Graduação 2011-2020. Coordenação de Pessoal de Nível Superior. Brasília, DF: CAPES, 2010. Disponível em:

https://www.capes.gov.br/images/stories/download/Livros-PNPG-Volume-I-Mont.pdf, Acesso em: 10 jan. 2017.

. Plano Nacional de Implementação das Diretrizes Curriculares Nacionais para a Educação das Relações étnico-Raciais e para o Ensino de História e Cultura Afro-brasileira e Africana. Diário Oficial da União. Brasília: Casa Civil da Presidência da República, 2009. Disponível em: http://portal.mec.gov.br/index.php?option=com_docman\&view=downloado wnload\&alias=10098-diretrizes-curriculares\&ltemid=30192, Acesso em: 17 jul. 2018.

Resolução N. 1/2004. Diretrizes Curriculares Nacionais Educação das Relações Étnico-Raciais e para o Ensino de História e Cultura Afro-Brasileira e Africana. Diário Oficial da União. Brasília: Casa Civil da Presidência da República, 2004. Disponível em: http://portal.mec.gov.br/cne/arquivos/pdf/res012004.pdf, Acesso em: 17 jul. 2018.

CAPES. Proposta do Programa da Universidade Federal de Bahia, 2017. Disponível em:

https://sucupira.capes.gov.br/sucupira/public/consultas/coleta/propostaPrograma/list aProposta.xhtm, Acesso em: 05 jul. 2018.

Disponível em:

Proposta do Programa da Universidade Federal de Ceará, 2017.

https://sucupira.capes.gov.br/sucupira/public/consultas/coleta/propostaPrograma/list aProposta.xhtm, Acesso em: 05 jul. 2018.

. Proposta do Programa da Universidade Federal do Rio Grande do

Norte, 2017. Disponível em:

https://sucupira.capes.gov.br/sucupira/public/consultas/coleta/propostaProgra ma/listaProposta.jsf, Acesso em: 18 jul. 2018, 
. Proposta do Programa da Universidade Federal de Pernambuco, 2017.

Disponível em:

https://sucupira.capes.gov.br/sucupira/public/consultas/coleta/propostaProgr ama/ listaProposta.jsf, Acesso em: 18 jul. 2018.

Proposta do Programa da Universidade Federal Rural de Pernambuco, 2017. Disponível em:

https://sucupira.capes.gov.br/sucupira/public/consultas/coleta/propostaProgr rama/ listaProposta.jsf, Acesso em: 18 jul. 2018.

BRITO, N. J. C. Formação de Professores e Relações Étnico-Raciais: estudo sobre as produções científicas do período de 2003-2013. Tese (Doutorado em Educação) - Programa de Pós-Graduação em Educação, UFPA, Belém, 2018.

COELHO, M. C.; COELHO, W. N. B. Dossiê: As leis e suas práticas: a diversidade em exercício. Revista História e Diversidade, v. 6, n. 1, p. 03-05, 2015.

COELHO, W. N. B.; SILVA, C. A. F. A produção intelectual docente na PósGraduação em Educação no Norte do Brasil: avanços e desafios. Educação Unisinos, Rio Grande do Sul, v. 20, n. 3, p. 387-399, set./dez., 2016.

CORRÊA; G. T.; RIBEIRO, V. M. B. A formação pedagógica no Ensino Superior e o papel da Pós-Graduação stricto sensu. Educação e Pesquisa, v. 39, n. 2, abr./jun. 2013.

CURTY, R. G. (Org.). Produção intelectual no ambiente acadêmico. Londrina: UEL/CIN, 2010.

FARIAS FILHO, L. M. O novo PNPG e a Educação Básica. Educação Revista, Belo Horizonte, v. 29, p. 289-295, jun. 2013.

FÁVERO, O. Pós-Graduação em educação: avaliação e perspectivas. Revista de Educação Pública, v. 20, n. 3, set./dez. 2009.

LOURENCO, C. D. S.; LIMA, M. C.; NARCISO, E. R. P. Formação pedagógica no ensino superior: o que diz a legislação e a literatura em Educação e Administração?. Avaliação, vol.21, n.3, p.691-718, 2016.

MOROSINI; M. C. A Pós-Graduação no Brasil: formação e desafios. Revista Argentina de Educación Superior, v. 1, p. 125-152, 2009.

NOSELLA, P. A pesquisa em educação: um balanço da produção da PósGraduação. Revista Brasileira de Educação, Rio de Janeiro, v. 5, n. 43, p. 177-203 jan./abr. 2010.

. Compromisso político e competência técnica: 20 anos depois. Educação e Sociedade, Campinas, v. 26, n. 90, p. 223-238, jan./abr. 2005. 
RAMALHO, B. L.; MADEIRA, V. P. C. A Pós-Graduação em educação no Norte e Nordeste: desafios, avanços e perspectivas. Revista Brasileira de Educação, Rio de Janeiro local, n. 30, p. 70-81 set./dez., 2005.

SANTOS, C. M. Tradições e Contradições da Pós-Graduação no Brasil. Educação e sociedade, Campinas, v. 24, n. 83, p. 627-641, 2003.

SANTOS, R. E. N. Escalas da ação política e movimentos sociais: o caso do movimento negro brasileiro e a emergência de políticas educacionais de combate ao racismo. GEOgraphia, v. 17, n. 33, p. 69-, 97, 2015.

SAVIANI, D. O dilema produtividade-qualidade na Pós-Graduação. Nuances: estudos sobre educação, São Paulo, ano XVII, v. 2, n. 18, p. 32-49, jan./dez., 2000.

SILVA, P. B. G. Ações Afirmativas na UFSCar: em busca da qualidade acadêmica com compromisso social. Políticas Educativas, v. 2, p. 41-53, 2008.

VALENTIN, S. S.; PINHO, V. A.; GOMES, N. L. Relações étnico-raciais, educação e produção do conhecimento: 10 anos do GT 21 da Anped. Belo Horizonte: Nandyala, 2012.

WASSEN, J.; PEREIRA, E. M. A.; BALZAN, N. C. Política de avaliação em programas de Pós-Graduação de excelência em educação. Atos de Pesquisa em Educação, v. 10, n. 1, p. 215-243, jan./abr., 2015. 